\title{
Artificial Neural Network Modeling of Healthy Risk Level Induced by Aircraft Pollutant Impacts around Soekarno Hatta International Airport
}

\author{
Salah Khardi ${ }^{1}$, Jermanto Setia Kurniawan ${ }^{2}$, Irwan Katili ${ }^{2}$, Setyo Moersidik ${ }^{2}$ \\ ${ }^{1}$ Transports and Environment Laboratory, French Institute of Science and Technology for Transport, Development and Networks \\ (IFSTTAR), Bron, France; ${ }^{2}$ Department of Civil Engineering, Faculty of Engineering, University of Indonesia, Kampus Baru UI, \\ Depok, Indonesia. \\ Email: Salah.khardi@ifsttar.fr
}

Received May $30^{\text {th }}, 2013$; revised July $2^{\text {nd }}, 2013$; accepted August $1^{\text {st }}, 2013$

Copyright (C) 2013 Salah Khardi et al. This is an open access article distributed under the Creative Commons Attribution License, which permits unrestricted use, distribution, and reproduction in any medium, provided the original work is properly cited.

\begin{abstract}
Aircraft pollutant emissions are an important part of sources of pollution that directly or indirectly affect human health and ecosystems. This research suggests an Artificial Neural Network model to determine the healthy risk level around Soekarno Hatta International Airport-Cengkareng Indonesia. This ANN modeling is a flexible method, which enables to recognize highly complex non-linear correlations. The network was trained with real measurement data and updated with new measurements, enhancing its quality and making it the ideal method for this research. Measurements of aircraft pollutant emissions are carried out with the aim to be used as input data and to validate the developed model. The obtained results concerned the improved ANN architecture model based on pollutant emissions as input variables. ANN model processes variables - hidden layers - and gives an output variable corresponding to a healthy risk level. This model is characterized by a 4-10-1 scheme. Based on ANN criteria, the best validation performance is achieved at epoch 28 from 34 epochs with the Mean Squared Error (MSE) of $9 \times 10^{-3}$. The correlation between targets and outputs is confirmed. It validated a close relationship between targets and outputs. The network output errors value approaches zero. Further research is needed with the aim to enlarge the scheme of the ANN model by increasing its input variables. This is one of the major key defining environmental capacities of an airport that should be applied by Indonesian airport authorities. These would institute policies to manage or reduce pollutant emissions considering population and income growth to be socially positive.
\end{abstract}

Keywords: Aircraft; Pollutant Emissions; Artificial Neural Network; Healthy Risk Level

\section{Introduction}

The continuing growth in air traffic and increasing public awareness have made environmental considerations one of the most critical aspects of commercial aviation. It is generally accepted that significant improvements to the environmental acceptability of aircraft will be needed if the long-term growth of air transport is to be sustained. This is an open issue. The release of exhaust gasses in the atmosphere is the second major environmental issue associated with commercial airliners. The expected doubling of the fleet in the next twenty years will certainly exacerbate the issue: the contribution of aviation is expected to increase by factor of 1.6 to 10 , depending on the fuel use scenario. Being conscious of this problem, engine manufacturers have developed low-emission combustors, and made them available as options. These combustors have been adopted by airlines operating in European airports with strict emissions controls, in Sweden and Switzerland, for example. Significant progress has been made with some individual pollutants rather than with others. Aircraft emissions have also declined over time when consider the emissions from transporting one passenger one mile. Current emissions regulations have focused on local air quality in the vicinity of airports and the research will also focus on the local impact of Aviation [1,2]. Emissions released during cruise in the upper atmosphere are recognized as an important issue with potentially severe long-term environmental consequences, and ICAO is actively seeking support for regulating them 
as well. Operations of aircraft are usually divided into two main parts [3]: The Landing-Take-off (LTO) cycle which includes all activities near the airport that take place below the altitude of 3000 feet $(914 \mathrm{~m})$. This therefore includes taxi-in and out, take-off, climb-out and approach-landing.

Cruise is defined as an activity that takes place at altitude above 3000 feet $(914 \mathrm{~m})$. No upper limit altitude is given. Cruise includes climb from the end of climb-out in the LTO cycle to the cruise altitude, cruise, and descent from cruise altitudes to the start of LTO operations of landing. Emissions from aircraft originate from fuel burned in aircraft engines [3]. Aircraft jet engines produce carbon dioxide $\left(\mathrm{CO}_{2}\right)$, water vapor $\left(\mathrm{H}_{2} \mathrm{O}\right)$, Nitrogen Oxides $\left(\mathrm{NO}_{\mathrm{x}}\right)$, Carbon Monoxide (CO), Oxides of sulfur $\left(\mathrm{SO}_{\mathrm{x}}\right)$, unburned or partially combusted hydrocarbons (also known as volatile organic compounds (VOC), particulates and other trace compounds [4]. A small subset of the VOCs and particulates are considered hazardous air pollutants (HAPs).

Aircraft engine emissions are roughly composed of about $70 \% \mathrm{CO}_{2}$, a little less than $30 \% \mathrm{H}_{2} \mathrm{O}$, and less than $1 \%$ each of $\mathrm{NO}_{\mathrm{x}}, \mathrm{CO}, \mathrm{SO}_{\mathrm{x}}, \mathrm{VOC}$, particulates, and other trace components including HAPs. Aircraft emissions, depending on whether they occur near the ground or at altitude, are primarily considered local air quality pollutants or greenhouse gases [4,5]. Water in the aircraft exhaust at altitude may have a greenhouse effect, and occasionally this water produces contrails, which also may have a greenhouse effect. About $10 \%$ of aircraft emissions of all types, except hydrocarbons and CO [6], are produced during airport ground level operations and during landing and takeoff. The bulk of aircraft emissions $(90 \%)$ occur at higher altitudes [4,7]. For hydrocarbons and CO, the split is closer to $30 \%$ ground level emissions and $70 \%$ at higher altitudes. Aircraft is not the only source of aviation emissions. Airport access and ground support vehicles produce similar emissions. Such vehicles include traffic to and from the airport, ground equipment that services aircraft, and shuttle buses and vans serving passengers.

Other emissions sources at the airport include auxiliary power units providing electricity and air conditioning to aircraft parked at airport terminal gates, stationary airport power sources, and construction equipment operating on the airport $[4,8]$. Emission from Combustion Processes $\mathrm{CO}_{2}$ - Carbon dioxide is the product of complete combustion of hydrocarbon fuels like gasoline, jet fuel, and diesel. Carbon in fuel combines with oxygen in the air to produce $\mathrm{CO}_{2} \cdot \mathrm{H}_{2} \mathrm{O}$-Water vapor is the other product of complete combustion as hydrogen in the fuel combines with oxygen in the air to produce $\mathrm{H}_{2} \mathrm{O} . \mathrm{NO}_{\mathrm{x}}$-Nitrogen oxides are produced when air passes through high temperature/high pressure combustion and nitrogen and oxygen present in the air combine to form $\mathrm{NO}_{\mathrm{x}}[4,5,8,9]$. HC-Hydrocarbons are emitted due to incomplete fuel combustion [6]. They are also referred to as volatile organic compounds (VOCs). Many VOCs are also hazardous air pollutants. $\mathrm{CO}-\mathrm{Carbon}$ monoxide is formed due to the incomplete combustion of the carbon in the fuel. $\mathrm{SO}_{\mathrm{x}}$-Sulfur oxides are produced when small quantities of sulfur, present in essentially all hydrocarbon fuels, combine with oxygen from the air during combustion $[4,8]$.

Particulates-small particles that form as a result of incomplete combustion, and are small enough to be inhaled, are referred to as particulates. Particulates can be solid or liquid. Ozone $-\mathrm{O}_{3}$ is not emitted directly into the air but is formed by the reaction of VOCs and $\mathrm{NO}_{\mathrm{x}}$ in the presence of heat and sunlight [5,9]. Ozone forms readily in the atmosphere and is the primary constituent of smog. For this reason it is an important consideration in the environmental impact of aviation [4,8]. Compared to other sources, aviation emissions are a relatively small contributor to air quality concerns both with regard to local air quality and greenhouse gas emissions. While small, however, aviation emissions cannot be ignored $[4,8]$. Emissions will be dependent on the fuel type, aircraft type, engine type, engine load and flying altitude. Two types fuel are used. Gasoline is used in small piston engines aircraft only. Most aircraft run on kerosene and the bulk of fuel used for aviation is kerosene. In general, there exist two types of engines: reciprocating piston engines and gas turbines [1-3,10-14].

Most emissions originate from the first category which covers the scheduled flights of ordinary aircraft. The ICAO is a United Nations intergovernmental body responsible for worldwide planning, implementation, and coordination of civil aviation. ICAO sets emission standards for jet engines. These are the basis of FAA's aircraft engine performance certification standards, established through EPA regulations. Currently ICAO has covered three approaches to quantifying aircraft engine emissions: two in detail and one in overview: Simple Approach, Advanced Approach and Sophisticated Approach $[1,2,11-13,15,16]$ :

- Simple Approach is the least complicated approach, requires the minimum amount of data, and provides the highest level of uncertainty often resulting in an over estimate of aircraft emissions. This approach considers the emission pollutant of $\mathrm{NO}_{\mathrm{x}}, \mathrm{CO}, \mathrm{HC}$, $\mathrm{SO}_{2}, \mathrm{CO}_{2}$.

- Advanced Approach reflects an increased level of refinement regarding aircraft types, EI calculations and TIM. This approach considers the emission pollutant of $\mathrm{NO}_{\mathrm{x}}, \mathrm{CO}, \mathrm{HC}, \mathrm{SO}_{2}$.

- Sophisticated Approach which is provided in overview, will be further developed in an update of this 
guidance $[1,2,11,12]$ and is expected to best reflect actual aircraft emissions.

\section{Calculation Method}

Calculation method is built following seven complementary and necessary steps.

\subsection{Runway Emission Method [1,2,11-13,17]}

For each hour get Aircraft Type, Runway and Arrival/ Departure flag from movements table. From aircraft table get for each aircraft Arrival Profile ID, Departure Profile ID, Engine ID and Engine Count. Based on Runway and Profile ID get profile segment data (Time-in-mode and Mode) from runway space table. From engine table get Engine Emission Indices based on Engine ID and Mode (takeoff-TO), climb-out (CL) or approach (AP). For each segment calculate emissions and add runway space block totals. Store each block total in hourly emissions table (hr_emis). Runway emissions include also runway roll emissions (takeoff roll and landing roll) and emissions released in the vertical plane above the runway (climb- out and approach). Additionally there is a pre-processor which intersects profile trajectories with runway space blocks (Figure 1).

\subsection{Thrust-Based Emission Calculator}

The Thrust-Based Emission Calculator (TBEC) is a Microsoft Access application which has been specially developed for Sourdine II [18] in order to calculate aircraft emissions resulting from the different SII procedures. It uses the ICAO Engine Exhaust Emissions Data Bank, which provides, for a large series of engine types, fuel flow $(\mathrm{kg} / \mathrm{s})$ and emission indices $(\mathrm{g} / \mathrm{kg}$ of fuel) at four specific engine power settings (from idle to full take-off power). The overall principle of TBEC consists of calculating (by interpolations) emission levels, based on the actual thrust along the vertical fixed-point profiles associated to the SII procedures. To calculate emission levels of different pollutants, it is necessary to have fuel flow information along the flight profiles. It was originally planned to approximate these by interpolations on input thrust values, as the ICAO databank provides fuel flow

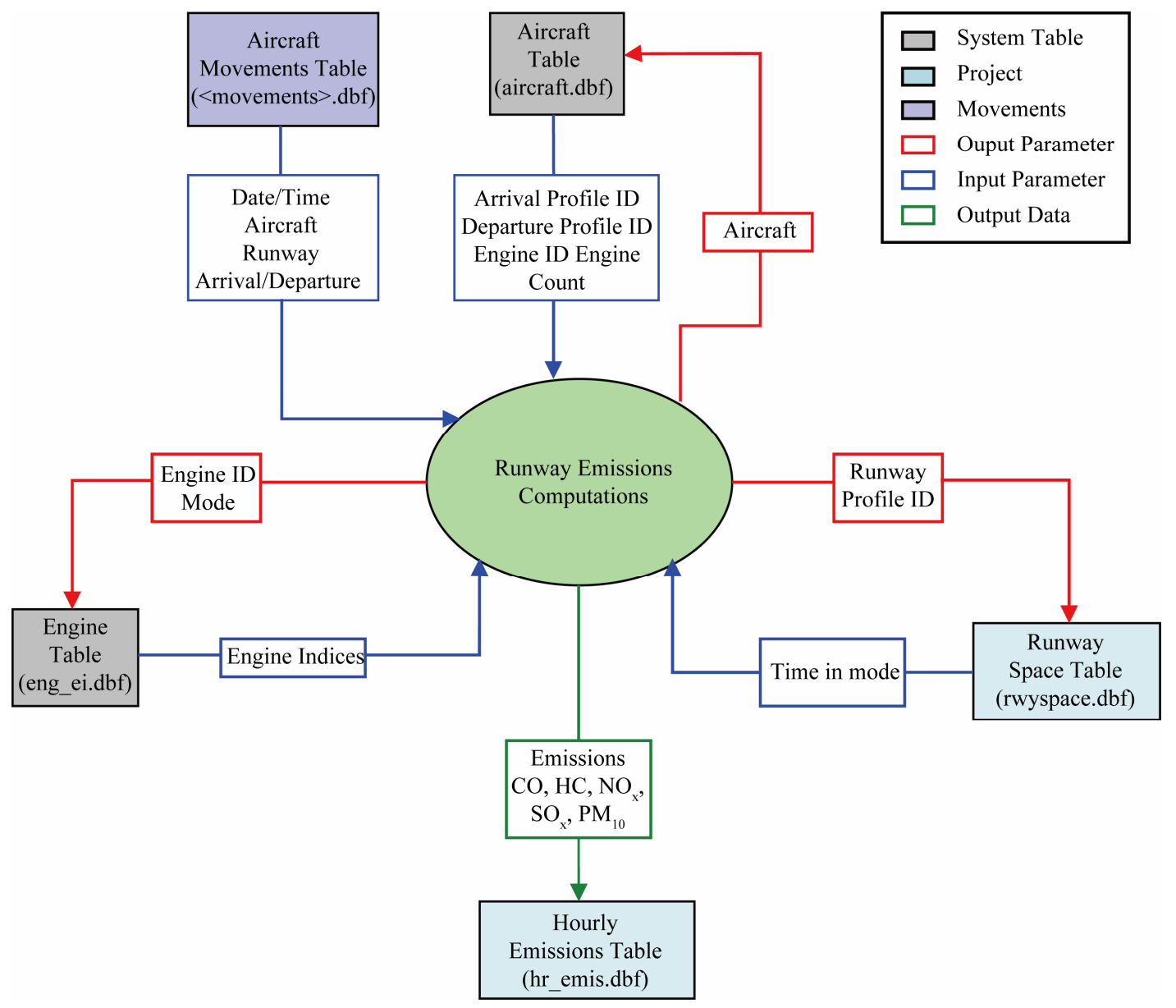

Figure 1. Runway emission calculation [1,2,11-13]. 
data associated to specific power settings. However, the International Civil Aviation Organization Committee on Aviation Environmental Protection (CAEP)'s Modeling Working Group (WG2) considered that estimating fuel flow based on thrust was unsatisfactory without having a greater knowledge of individual aircraft/engine performance parameters, data that is not yet readily available. Consequently, realistic fuel flow data have been supplied by Airbus for all the studied SII procedures (along with the baseline procedures) and for the eight Airbus aircraft. These fuel flow data have been incorporated, as an additional parameter. Based on the fuel flow and thrust values along the flight profiles, TBEC calculates total fuel burn (a straight forward process), and emission levels of different pollutants. Calculation of arrival emissions stops at touchdown since the fuel-flow data available stop at that point. Reverse thrust emissions are not taken into account. These would vary as a function of the landing speed of the aircraft, which is very slightly higher in the Sourdine II procedures than the baseline due to the different landing configurations used. TBEC inputs: TBEC calculates fuel burn and emission levels for the fixed-point profiles of the SII flight profile database, which include the additional fuel flow parameter (Airbus aircraft only). These input fixed-point profiles provide altitude (ft), speed (kts), corrected net thrust (lbs) and fuel flow $(\mathrm{kg} / \mathrm{s})$ as a function of the ground distance (ft) from brake release (for departures), or to touchdown (for arrivals).

For a given flight profile, TBEC calculates total fuel burn and total emissions (in $\mathrm{kgs}$ ) of the following components: $\mathrm{HC}, \mathrm{CO}, \mathrm{NO}_{\mathrm{x}}, \mathrm{SO}_{2}, \mathrm{CO}_{2}, \mathrm{H}_{2} \mathrm{O}, \mathrm{VOC}$, total organic gases (TOG). VOC are Acetaldehyde, Acrolein, POM16PAH, POM7PAH, Styrene. TOG are Formaldehyde, Propianaldehyde, Toluene, Xylene, 1-3Butadiene, Benzene, Ethylbenzene. The calculation of total fuel burn is a straight forward process: it is obtained by the time integration of the input fuel flow data along the profile. $\mathrm{HC}, \mathrm{CO}$ and $\mathrm{NO}_{\mathrm{x}}$ are obtained by linear interpolations in the ICAO databank, using as input data the corrected net thrust and the fuel flow on the successive segments of the profile. $\mathrm{CO}_{2}, \mathrm{SO}_{2}$ and $\mathrm{H}_{2} \mathrm{O}$ emissions are proportional to fuel burn (or fuel flow), and are obtained using emission coefficients $\left(\mathrm{kg} / \mathrm{kg}\right.$ fuel flow, or $\mathrm{g} / \mathrm{kg}$ fuel flow for $\left.\mathrm{SO}_{2}\right)$. The VOC and TOG emissions are obtained in a similar way from the calculated emissions of HC. All these emission coefficients are independent of the engine type. Calculation principle: The flight profile is defined by a series of small segments, each segment being defined by two consecutive points of the fixed-point profile. The overall calculation principle consists of estimating the fuel burn and emission levels produced by each segment, and summing them (over the flight profile) to obtain the total fuel burn and emissions of each pollutant.

\subsection{Fuel Burn}

The fuel burn on a trajectory segment $\mathrm{FB}_{\text {seg }}$ is calculated as follows:

$$
\mathrm{FB}_{\text {seg }}=\Delta \mathrm{T}_{\text {seg }} \times \mathrm{FF}_{\text {seg }}
$$

where

- $\Delta \mathrm{T}_{\text {seg }}$ is the duration (in seconds) of the flight segment. $\Delta \mathrm{T}_{\text {seg }}$ is calculated using the distance between the two end-points of the segment, divided by the average speed of the aircraft on the segment;

- $\mathrm{FF}_{\text {seg }}$ is the average fuel flow on the segment $(\mathrm{kg} / \mathrm{s})$, calculated using the input fuel flow values at the two end-points of the segment.

\section{4. $\mathrm{HC}, \mathrm{CO}$ and $\mathrm{NO}_{\mathrm{x}}$}

The ICAO Engine Exhaust Emissions Data Bank provides emission indices $(\mathrm{g} / \mathrm{kg}$ fuel flow) at four different power setting levels, namely: Take-Off, Climb-Out, Approach, and Idle. These four power states correspond to $\mathrm{a} \%$ age of $\mathrm{F}_{\mathrm{oo}}$, the maximum engine thrust available for take-off under normal operating conditions at ISA sea level static conditions. By definition, the four tabulated power settings correspond respectively to $100 \%, 85 \%$, $30 \%$ and $7 \%$ of $\mathrm{F}_{\mathrm{oo}}$ (Similar to ALAQS [17]. The emissions of $\mathrm{HC}, \mathrm{CO}$ and $\mathrm{NO}_{\mathrm{x}}$ on a segment are calculated through a linear interpolation between the above tabulated emission data. The different steps of the process are described below. The Emission Indices EI $\left(\mathrm{P}_{\mathrm{i}}\right)$ of each pollutant provided by the ICAO data bank at the four power settings are converted into segment-specific emission flow $\mathrm{EF}_{\text {seg }}\left(\mathrm{P}_{\mathrm{i}}\right)$ as follows:

$$
\mathrm{EF}_{\text {seg }}\left(\mathrm{P}_{\mathrm{i}}\right)=\mathrm{EI}\left(\mathrm{P}_{\mathrm{i}}\right) \times \mathrm{FF}_{\text {seg }}
$$

where

- $\mathrm{EF}_{\text {seg }}\left(\mathrm{P}_{\mathrm{i}}\right)$ is the emission flow for the segment associated to power setting $P_{i}$ (in $g / s$ ). $P_{i}$ is one of the tabulated engine power settings for which emission indices are provided in the data bank $(7 \%, 30 \%, 85 \%$ or $100 \%)$. EI $\left(\mathrm{P}_{\mathrm{i}}\right)$ is the emission indices associated to power setting $P_{i}$ (in $g / k g$ of fuel). $F_{\text {seg }}$ is the average fuel flow on the segment (in $\mathrm{kg} / \mathrm{s}$ ), calculated using the input fuel flow values at the two end-points of the segment. The segment-specific power setting parameter $\mathrm{P}_{\text {seg }}$, at which the emission levels will be interpolated, is approximated as follows:

$$
\mathrm{P}_{\text {seg }}=\frac{\mathrm{CNT}_{\text {seg }}}{\text { MaxStaticThrust }} \times 100
$$

where

- $\mathrm{P}_{\mathrm{seg}}$ is the segment-specific power setting (\%); 
- $\mathrm{CNT}_{\text {seg }}$ is the average corrected net thrust (lb) on the segment, calculated using the input CNT values at the two end-points of the segment;

- MaxStaticThrust is the available engine-specific maximum sea level static thrust.

The emission level of a given pollutant on the segment $\mathrm{EL}_{\text {seg }}$ is expressed as:

$$
\begin{aligned}
\mathrm{EL}_{\text {seg }}= & \Delta \mathrm{T}_{\text {seg }} \times\left[\mathrm{EL}_{\text {seg }}\left(\mathrm{P}_{\mathrm{i}}\right)\right. \\
& \left.+\frac{\mathrm{P}_{\text {seg }}-\mathrm{P}_{\mathrm{i}}}{\mathrm{P}_{\mathrm{i}+1}-\mathrm{P}_{\mathrm{i}}}\left(\mathrm{EF}_{\text {seg }}\left(\mathrm{P}_{\mathrm{i}+1}\right)-\mathrm{EF}_{\text {seg }}\left(\mathrm{P}_{\mathrm{i}}\right)\right)\right]
\end{aligned}
$$

where

- $\mathrm{EL}_{\text {seg }}$ is the emission level of the pollutant produced on the segment (g);

- $\Delta \mathrm{T}_{\mathrm{Teg}}$ is the duration (in seconds) of the flight segment. $\Delta \mathrm{T}_{\text {seg }}$ is calculated using the distance between the two end-points of the segment, divided by the average speed of the aircraft on the segment;

- $\mathrm{P}_{\text {seg }}$ is the segment-specific power setting (\%);

- $\mathrm{P}_{\mathrm{i}}$ and $\mathrm{P}_{\mathrm{i}+1}$ are the two tabulated power setting values bounding $\mathrm{P}_{\text {seg }}(\%)$;

- $\mathrm{EF}_{\text {seg }}\left(\mathrm{P}_{\mathrm{i}}\right)$ and $\mathrm{EF}_{\text {seg }}\left(\mathrm{P}_{\mathrm{i}+1}\right)$ are the emission flow values $(\mathrm{g} / \mathrm{s})$ associated to $\mathrm{P}_{\mathrm{i}}$ and $\mathrm{P}_{\mathrm{i}+1}$.

\section{5. $\mathrm{CO}_{2}, \mathrm{SO}_{2}, \mathrm{H}_{2} \mathrm{O}$}

Those emission levels are directly proportional to the calculated fuel burn and are estimated using the following emission coefficients:

\begin{tabular}{cc}
\hline Component & Emission coefficient \\
\hline $\mathrm{CO}_{2}$ & $3.149(\mathrm{~kg} / \mathrm{kg}$ fuel $)$ \\
$\mathrm{SO}_{2}$ & $0.84(\mathrm{~g} / \mathrm{kg}$ fuel $)$ \\
$\mathrm{H}_{2} \mathrm{O}$ & $1.23(\mathrm{~kg} / \mathrm{kg}$ fuel $)$ \\
\hline
\end{tabular}

Limitations/validity: The first limitation of TBEC is that it does not take into account the variation of the emission indices with altitude due to temperature and pressure changes. Indeed, the ICAO databank provides emission indices for ISA conditions; these are, however, assumed to be valid for altitudes below $3000 \mathrm{ft}$.

A sophisticated method has to be developed; it would allow the modeling of the effects of non-ISA temperature and pressure conditions at the airport. Another limitation is due to the assumption that emission indices vary linearly with the thrust level, which is obviously not the case in real life. It would also be necessary to model non-linear variations between thrust settings in the ICAO databank. The method to be developed will be able to calculate the power setting parameter required to perform in- terpolations. Further investigation of this point is required.

\subsection{Time-in-Mode Calculations}

The duration of the approach and climb out modes depends largely on the mixing height selected. EPA guidance provides approach and climb out times for a default mixing height of 3000 feet, and a procedure for adjusting these times for different mixing heights. The adjustments are calculated using the following equations:

$$
\begin{aligned}
\text { Climb out }: \operatorname{TIM}_{\text {adj }} & =\operatorname{TIM}_{\text {dft }}\left[\frac{\text { Mixing Height }-500}{3000-500}\right] \\
\text { Approach }: \operatorname{TIM}_{\text {adj }} & =\operatorname{TIM}_{\text {dft }}\left[\frac{\text { Mixing Height }}{3000}\right]
\end{aligned}
$$

where TIM $_{\mathrm{adj}}$ is the adjusted time-in-mode for approach or climb out, and $\operatorname{TIM}_{\text {dfft }}$ is the default time-in-mode. Mixing height is by default given in feet. The equation for climb out assumes that 500 feet is the demarcation between the takeoff and climb out modes. Expressed in metric units, the approach and climb out adjustment equations are as follows:

$$
\begin{aligned}
\text { Climb out }: \mathrm{TIM}_{\text {adj }} & =\operatorname{TIM}_{\text {dft }}\left[\frac{\text { Mixing Height }-152}{915-152}\right] \\
\text { Approach }: \mathrm{TIM}_{\text {adj }} & =\operatorname{TIM}_{\text {dft }}\left[\frac{\text { Mixing Height }}{915}\right]
\end{aligned}
$$

Default mixing height is 915 meters, with the demarcation between approach and climb out modes at 152 meters. Consistent with EPA guidance $[4,8,19]$, a fourminute default approach time was assumed for this study.

\subsection{Emissions Calculation}

The weighted-average emission factor represents the average emission factor per LTO cycle for all engine models used on a particular type of aircraft. The weightedaverage emission factor per 1000 pounds of fuel is calculated as follows:

$$
\overline{\mathrm{EF}}_{\mathrm{ijk}}=\sum_{\mathrm{m}=1}^{\mathrm{NM} \mathrm{M}_{\mathrm{j}}}\left(\mathrm{X}_{\mathrm{mj}} \cdot \mathrm{EF}_{\mathrm{imk}}\right)
$$

where $\mathrm{EF}_{\mathrm{imk}}$ is the emission factor for pollutant $\mathrm{i}$, in pounds of pollutant per 1000 pounds of fuel (or kilograms pollutant per 1000 kilograms fuel), for engine model $\mathrm{m}$ and operating mode $\mathrm{k} . \mathrm{X}_{\mathrm{mj}}$ is the fraction of aircraft type $\mathrm{j}$ with engine model $\mathrm{m}$; and $\mathrm{NM}_{\mathrm{j}}$ is the total number of engine models associated with aircraft type $j$. Note that, for a given aircraft type $\mathrm{j}$, the sum of $X_{\mathrm{mj}}$ for all engine models associated with aircraft $j$ is 1 . Total emissions per LTO cycle for a given aircraft types are 
calculated using the following equation:

$$
\mathrm{E}_{\mathrm{ij}}=\mathrm{TIM}_{\mathrm{jk}} \cdot \frac{\mathrm{FF}_{\mathrm{jk}}}{1000} \cdot \mathrm{EF}_{\mathrm{ijk}} \cdot \mathrm{NE}_{\mathrm{j}}
$$

where $\operatorname{TIM}_{\mathrm{jk}}$ is the time in mode $\mathrm{k}$ (min) for aircraft type j. $\mathrm{F}_{\mathrm{jk}}=$ fuel flow for mode $\mathrm{k}(\mathrm{lbs} / \mathrm{min}$ or $\mathrm{kg} / \mathrm{min}$ ) for each engine used on aircraft type $\mathrm{j} . \mathrm{EF}_{\mathrm{ijk}}=$ weighted-average emission factor for pollutant $i$, in pounds of pollutant per 1000 pounds of fuel (kilograms pollutant per 1000 kilograms fuel), for aircraft type $\mathrm{j}$ in operating mode $\mathrm{k}$. $\mathrm{NE}_{\mathrm{j}}$ is the number of engines on aircraft type j. Once the preceding calculations are performed for each aircraft type, total emissions for that aircraft type are computed by multiplying the emissions for one LTO cycle by the number of LTO cycles at a given location:

$$
\mathrm{E}_{\mathrm{i}}=\left(\mathrm{E}_{\mathrm{ij}} \cdot \mathrm{LTO}_{\mathrm{j}}\right)
$$

where $E_{i j}$ is the total emissions for pollutant $i$ from air- craft type j. $\mathrm{LTO}_{\mathrm{j}}=$ the number of LTOs for aircraft type j. Total emissions for each aircraft type are then summed to yield total commercial exhaust emissions for the facility as shown below:

$$
\mathrm{ET}_{\mathrm{i}}=\sum_{\mathrm{j}=1}^{\mathrm{N}}\left(\mathrm{E}_{\mathrm{ij}} \cdot \mathrm{LTO}_{\mathrm{j}}\right)
$$

where $\mathrm{ET}_{\mathrm{i}}$ is the total emissions for pollutant $\mathrm{i}$ from all aircraft types. $E_{i j}$ is the emissions of pollutant $i$ from aircraft type $\mathrm{j}$. $\mathrm{LTO}_{\mathrm{j}}$ is the number of LTOs for aircraft type $\mathrm{j}$; and $\mathrm{N}$ the total number of aircraft types.

Functional Flow-Emissions: Overall, the fundamental usage of EDMS $[4,8,10]$ is to first perform an emissions inventory [20], after which the user can chose to continue to model the dispersion of the emitted pollutants calculated. As shown in Figure 2, to perform an emissions inventory the user would follow the following steps:

- Set up the study by adding scenarios and airports, and

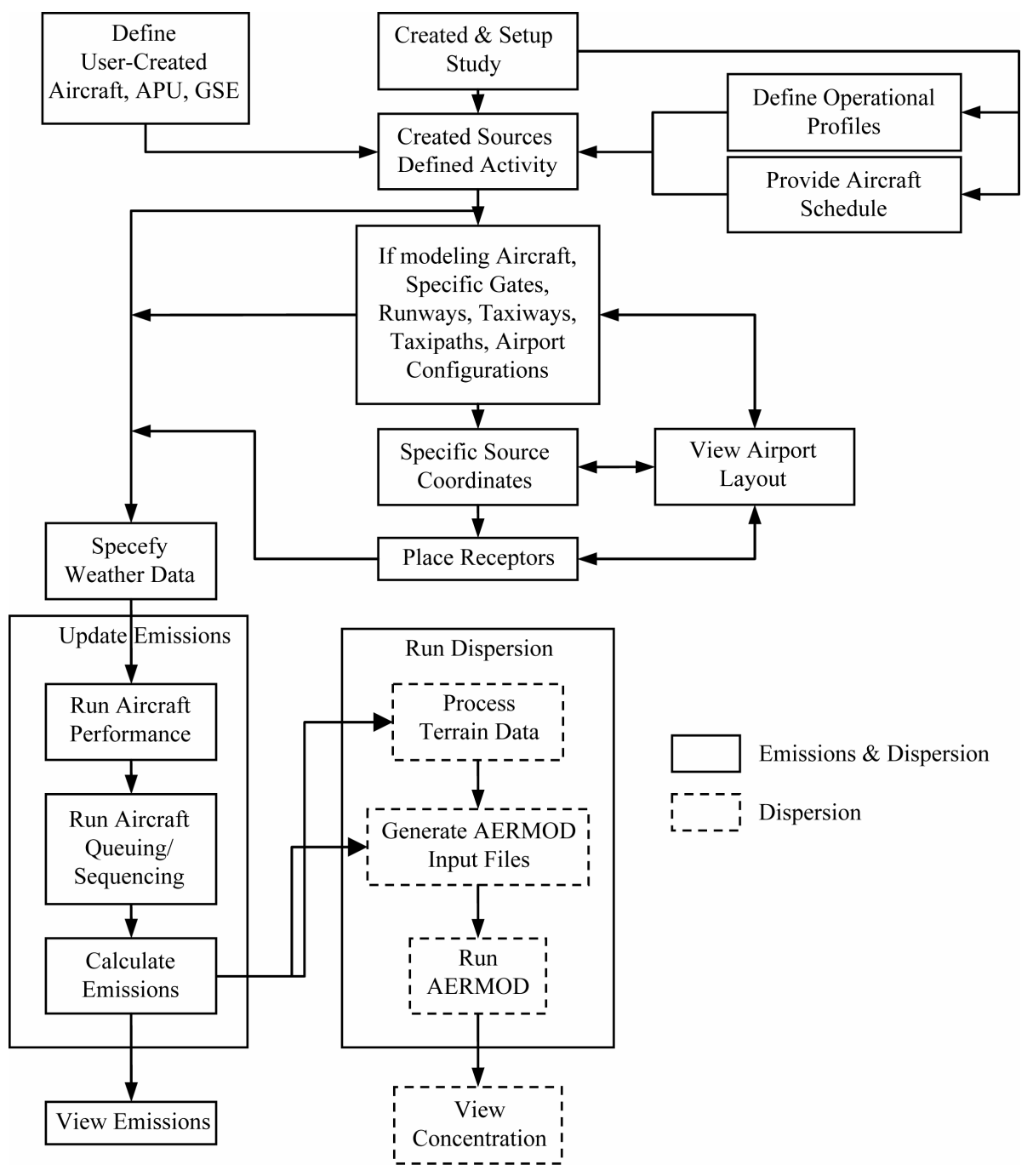

Figure 2. Functional flow. 
choose which modeling options to use.

- Define all emissions sources, including operational usage.

- Define the airport layout if sequence modeling was selected.

- Select a weather option: annual average or hourly (requires running AERMET).

- Select Update Emissions Inventory.

The simplest way to generate an emissions inventory and obtain a course estimate of the total annual emissions is to perform the first two steps, and use the ICAO/EPA default times in mode along with the default operational profiles, and the annual average weather from the EDMS airports database $[3,4,8,10,19,20]$. Doing so would only consider the total number of operations for the entire year without regard to when those operations occurred. If a more precise modeling of the aircraft taxi times using the Sequencing module is desired (required if dispersion will be performed), then the user must define the airport gates, taxiways, runways, taxi paths (how the taxiways and runways are used) and configurations (weather dependent runway usage). The resulting emissions values can be viewed by selecting Emissions Inventory on the View menu. These results can be printed by selecting Print under the File menu while viewing the emissions inventory.

\section{Artificial Neural Network Methodology}

Artificial neural networks are a very simplified version of real neural networks [21-24]. The human nervous system consists of $10^{11}$ to $10^{12}$ nerve cells and is able to carry out $10^{12}$ to $10^{13}$ "switching processes"- a complexity that cannot be rebuilt technically. Nevertheless, it is possible to understand the principles and to reconstruct a few cells that simulate the most important processes. In the year 1943, Warren McCulloch and Walter Pitts showed in their paper "A logical calculus of the ideas immanent in nervous activity" that even simple neural networks are able to calculate any arithmetic or logical function. 1957, Frank Rosenblatt et al. developed the first successful neuro-computer, the so-called "Mark 1 perceptron", which was able to recognize simple patterns. Neural networks on the base of back-propagation were developed in the early seventies and still are today the most popular networks [21-24].

A neural network can be described as a "black box" to which no interference takes place and whose concrete behavior is invisible [22,23]. Summarized, there are three principal tasks the network has to fulfill (Figure 3):

There are many types of ANN. Many new ones are being developed (or at least variations of existing ones). Networks based on supervised and unsupervised learning [22-25].

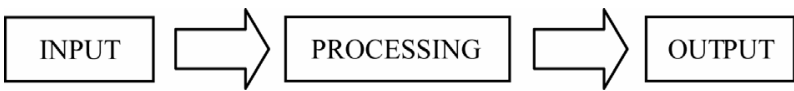

Figure 3. The three principal tasks of a neuron.

Supervised Learning: The network is supplied with a sequence of both input data and desired (target) output data network is thus told precisely by a "teacher" what should be emitted as output. The teacher can during the learning phase "tell" the network how well it performs ("reinforcement learning") or what the correct behavior would have been ("fully supervised learning") [22-25].

Self-Organization or Unsupervised Learning: A training scheme in which the network is given only input data, network finds out about some of the properties of the data set, learns to reflect these properties in its output. E.g. the network learns some compressed representation of the data. This type of learning presents a biologically more plausible model of learning. What exactly these properties are, that the network can learn to recognise, depends on the particular network model and learning method $[24,25]$.

Networks based on Feedback and Feed-forward connections: The following shows some types in each category.

Unsupervised Learning.

Feedback Networks:

1) Binary Adaptive Resonance Theory (ART1)

2) Analog Adaptive Resonance Theory (ART2, ART2a)

3) Discrete Hopfield (DH)

4) Continuous Hopfield $(\mathrm{CH})$

5) Discrete Bidirectional Associative Memory (BAM)

6) Kohonen Self-organizing Map/Topology-preserving map (SOM/TPM)

Feedforward-only Networks:

1) Learning Matrix (LM)

2) Sparse Distributed Associative Memory (SDM)

3) Fuzzy Associative Memory (FAM)

4) Counterprogation (CPN)-Supervised Learning

5) Feedback Networks:

- Brain-State-in-a-Box (BSB)-Fuzzy Congitive Map (FCM)

- Boltzmann Machine (BM)

- Backpropagation through time (BPTT)

6) Feedforward-only Networks:

- Perceptron-Adaline-Madaline

- Backpropagation (BP)-Artmap

- Learning Vector Quantization (LVQ)

- Probabilistic Neural Network (PNN)

- General Regression Neural Network (GRNN)

Methodology: Training, Testing and Validation Dataset

In the ANN methodology, the sample data is often 
subdivided into training, validation, and test sets. The distinctions among these subsets are crucial. Ripley [26] defined the following:

1) Training set: A set of examples used for learning that is to fit the parameters (weights) of the classifier.

2) Validation set: A set of examples used to tune the parameters of a classifier, for example to choose the number of hidden units in a neural network.

3) Test set: A set of examples used only to assess the performance (generalization) of a fully specified classifier.

Neural networks are the only tools that fulfill all characteristics as shown in Table 1.

Method for measurement, prediction and assessment of environmental problems such as aircraft pollutant emissions has been carried out. The use of certain meth- ods will require justification and reliability that must be demonstrated and proven. Various methods have been adopted for the assessment of aircraft annoyances.

The use of different and separate methodology causes a wide variation in results and there are some lacks of information. Assessment methods show different approaches with different levels of uncertainty as well. This uncertainty factor has seen from the value of the index that is different from any used method. Because of these problem and the recurrently exists no research activity on risk human impact from aircraft emissions near the airport, it propose in this research to develop the model of aircraft impact by combining different inputs, in particular concentration of pollutants (Figure 4) using Artificial Neural.

Network to determine the healthy risk of people around

Table 1. The advantages of neural networks.

\begin{tabular}{|c|c|c|c|c|c|c|}
\hline \multirow[b]{2}{*}{ Method } & \multicolumn{6}{|c|}{ Characteristics } \\
\hline & $\begin{array}{l}\text { Diffusive sampling } \\
\text { measurements } \\
\text { as input? }\end{array}$ & $\begin{array}{l}\text { High accuracy } \\
\text { of results? }\end{array}$ & $\begin{array}{l}\text { Ability to } \\
\text { incorporate the } \\
\text { most important } \\
\text { parameters? }\end{array}$ & Easy to handle? & $\begin{array}{c}\text { Short } \\
\text { computing time? }\end{array}$ & $\begin{array}{l}\text { Update and } \\
\text { enhancement } \\
\text { possible? }\end{array}$ \\
\hline Dispersion Modeling & & $\mathrm{X}$ & & & & \\
\hline Interpolation & $\mathrm{X}$ & & & $\mathrm{X}$ & $\mathrm{X}$ & \\
\hline $\begin{array}{l}\text { Interpolation with add } \\
\text { variable }\end{array}$ & $\mathrm{X}$ & & & $\mathrm{X}$ & $\mathrm{X}$ & \\
\hline Regression models & $\mathrm{X}$ & $\mathrm{X}$ & $\mathrm{X}$ & $\mathrm{X}$ & & \\
\hline Neural networks & $\mathrm{X}$ & $\mathrm{X}$ & $\mathrm{X}$ & $\mathrm{X}$ & $\mathrm{X}$ & $\mathrm{X}$ \\
\hline
\end{tabular}

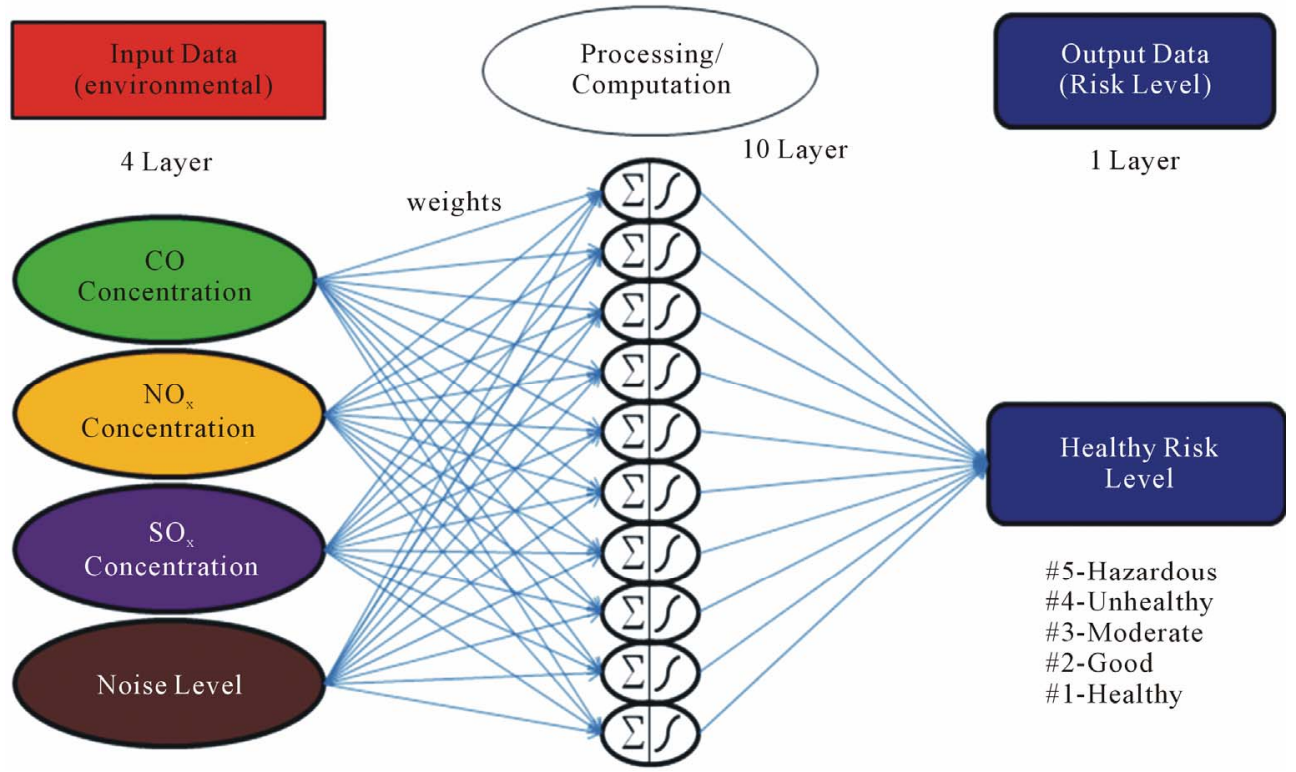

Summation and transfer function (processing element)

Figure 4. The suggested ANN model. 
the airport so we can manage the land use around the airport based on the healthy risk level. But the questions are how to combine pollutant and noise emission $[15,16]$, which method that would be reliable to use for quantifying the pollutant and noise emissions, how about the accuracy and the uncertainty of model that would be reliable, how about the balanced approach between economic, operational and environmental capacities, how far the zoning area of the pollutant and noise emission that affecting the people around airport, and what do we have as model to combine pollutant and noise emissions.

Based on the problem, it will be carried out the research on how to develop model of aircraft pollutant and noise emissions, which is the most suitable approach to be used, both for the assessment of pollutant and noise emissions and also the combination of those methods of assessment. To validate the developed model, it applies the measurement of noise and pollutant emissions at Soekarno Hatta International Airport-Cengkareng Indonesia.

The methodology will be used for assessing aircraft pollutant in this research is the ICAO methodology because of emission factors used are based on engine certification data in the ICAO Engine Exhaust Emission Databank that contains data sets of thrust (engine performance), fuel flow and emissions of components $\mathrm{CO}, \mathrm{NO}_{\mathrm{x}}$ and $\mathrm{SO}_{\mathrm{x}}$. Since ICAO has the approaches more widely used by various countries so that the concept of balanced approach will use for the assessment of Soekarno-Hatta International airport to assess the level of pollutant and noise emissions around airport with considering the future prospects of aircraft technologies.

ANN modeling is a flexible method, which enables one to recognize highly complex non-linear correlations [22]. Statistical assumptions like normal distribution are not necessary, which makes them easy to handle in principle. The network can be trained with real measurement data and updated with new measurements, enhancing its quality and making it the ideal method for the purpose of this research.

Data has been collected into two parts: Primary Data and Secondary Data. The Primary data consisted in noise and pollutant emissions measurement at Soekarno Hatta International Airport. The Secondary Data consist of Physical Data of airport, Air Traffic/Distribution of type of flight (time of flight/day) for one year, Topography Data and Weather Data. Emission and Dispersion of Modeling System (EDMS) has been carried out with concentration grid space $1 \mathrm{~km}^{2}$.

\section{Input variables:}

The new model ANN is used 1 layer input data with four input variables. Those input variables are noise level in decibel $(\mathrm{dB})$ unit and concentration of pollutant emis- sions $\left(\mathrm{CO}, \mathrm{NO}_{\mathrm{x}}\right.$, and $\left.\mathrm{SO}_{\mathrm{x}}\right)$ in $\mathrm{ug} / \mathrm{m}^{3}$ unit. Input element was obtained from EDMS calculate using air traffic data in the year 2009 and its extrapolation for 2012 at Soekarno Hatta Airport. 70\% of the input data set is presented to the network during training, so that the network can be adjusted according to its error.

$15 \%$ data are used to measure the network generalization and to halt the network when generalization stops improving. Remaining data performs testing of an independent measure of network performance during and after training. The training stops when gives a higher accuracy value with minimum training and testing errors.

\section{Processing variable:}

In process layer, proposed model used 1 hidden layer with 10 neurons which is the best architecture model ANN that obtain from tool ANN after several times process using sigmoid activation where the sigmoid activation function is the best performances in ANN. It can be described by the mathematical relationship $1 /\left(1+\mathrm{e}^{-\mathrm{x}}\right)$. Weight and Bias values is shown in Tables 2 and $\mathbf{3}$.

\section{Output variable:}

One layer for output layer was used to determine the healthy risk level as a target where the level has 5 healthy risks level that effect from aircraft noise and pollutant.

The Levenberg-Marquadt (LM) training algorithm outperformed in this research by training the high dimensional data in 34 epochs with the time of 1 second. The performance measures and outcome of the network are depicted below.

\begin{tabular}{cc}
\hline Number of Epochs & 34 \\
Training (R) & 0.97 \\
Testing (R) & 0.95 \\
Validation (R) & 0.95 \\
Mean Squared Error & Less than $1 \%$ \\
\hline
\end{tabular}

The error measures like Mean Squared Error (MSE) are recorded. MSE is the mean of the squared error between the desired output and the actual output of the neural network. The MSE is computed as follows.

$$
\mathrm{MSE}=\frac{\sum_{\mathrm{j}=0}^{\mathrm{P}} \sum_{\mathrm{i}=0}^{\mathrm{N}}\left(\mathrm{d}_{\mathrm{ij}}-\mathrm{y}_{\mathrm{ij}}\right)^{2}}{\mathrm{NP}}
$$

where $\mathrm{P}$ is the number of output processing elements.

$\mathrm{N}$ : the number of exemplars in the training data set;

$y_{\mathrm{ij}}$ : the estimated network emissions output for exemplar $i$ at processing element $j$;

$d_{i j}$ the actual output for emissions exemplar $i$ at processing element $\mathrm{j}$. In this research the obtained MSE value is less than $1 \%$ which was attained at 28 th epoch. There are 3 criteria based on ANN validation that choose to 
Pollutant Impacts around Soekarno Hatta International Airport

Table 2. Healthy risk level.

\begin{tabular}{|c|c|c|c|c|c|}
\hline \multirow{2}{*}{ Risk Score } & \multirow{2}{*}{ Level } & \multicolumn{3}{|c|}{ Pollutant Emissions } & \multirow{2}{*}{$\begin{array}{l}\text { Noise }(\mathrm{dB}) \text { Additional } \\
\text { and not necessary input }\end{array}$} \\
\hline & & $\mathrm{CO}\left(\mu \mathrm{g} / \mathrm{m}^{3}\right)$ & $\mathrm{NO}_{\mathrm{x}}\left(\mu \mathrm{g} / \mathrm{m}^{3}\right)$ & $\mathrm{SO}_{x}\left(\mu \mathrm{g} / \mathrm{m}^{3}\right)$ & \\
\hline$\# 5$ & Hazardous & $>200$ & $>200$ & $>200$ & $>85$ \\
\hline$\# 4$ & Unhealthy & $100-200$ & $99.64-200$ & $85.8-200$ & $70-85$ \\
\hline$\# 3$ & Moderate & $50-100$ & $50-99.64$ & $50-85.8$ & $60-70$ \\
\hline$\# 2$ & Good & $25-50$ & $25-50$ & $25-50$ & $50-60$ \\
\hline$\# 1$ & Healthy & $<25$ & $<25$ & $<25$ & $<50$ \\
\hline
\end{tabular}

Table 3. Network weights and bias values.

\begin{tabular}{|c|c|c|c|c|c|c|c|c|}
\hline \multicolumn{6}{|c|}{ Weights } & \multicolumn{3}{|c|}{ Bias } \\
\hline & \multicolumn{4}{|c|}{ Input Hidden (IW) } & \multirow[b]{2}{*}{$\begin{array}{l}\text { Hidden Output } \\
\text { (LW) }\end{array}$} & & \multirow[b]{2}{*}{$\left(b^{1}\right)$} & \multirow[b]{2}{*}{$\left(b^{2}\right)$} \\
\hline & $\mathrm{CO}$ & $\mathrm{NO}_{\mathrm{x}}$ & $\mathrm{SO}_{\mathrm{x}}$ & $\begin{array}{c}\text { Noise: } \\
\text { additional index }\end{array}$ & & & & \\
\hline w1 & 0.1407 & -0.35259 & 2.2921 & -1.1287 & 1.2221 & b1 & 2.1849 & 1.2555 \\
\hline w2 & -1.4491 & -0.18607 & -1.8873 & -0.26701 & 1.1295 & b2 & 2.0254 & \\
\hline w3 & 1.3516 & 2.9137 & 0.27905 & 0.89349 & 2.3592 & B3 & -2.8272 & \\
\hline w4 & 1.4867 & -0.48544 & -1.5046 & -1.5885 & -0.75403 & b4 & -1.1238 & \\
\hline w5 & -1.2303 & -0.84468 & 1.1476 & 1.0959 & -3.8315 & b5 & 0.73 & \\
\hline w6 & 0.93944 & 0.82249 & -1.0546 & 2.368 & -0.20789 & b6 & -2.4039 & \\
\hline w7 & -0.37134 & 0.88173 & -0.88702 & -1.3128 & -1.1142 & b7 & -0.28432 & \\
\hline w8 & -0.18717 & -1.8745 & 0.024024 & 5.5257 & 3.3151 & b8 & 3.8534 & \\
\hline w9 & -0.8133 & 1.2728 & 0.49045 & 1.2881 & 1.0377 & b9 & -2.834 & \\
\hline w10 & 1.4671 & 2.4003 & 0.22196 & 0.2502 & -0.77638 & b10 & 3.7339 & \\
\hline
\end{tabular}

validate the proposed of new model. Criteria 1 (Figure 5) is based on performance, Criteria 2 (Figure 6) is based on Regression R Value and Criteria 3 (Figure 7) is based on networks output errors. All Criteria give a best result of proposed ANN network. In Criteria 1, best validation performance is achieved at epoch 28 from 34 epochs (Mean Squared Error is 0.0093521). The correlation (Criteria 2) between target and output is validated at $\mathrm{R}=$ 0.95756 , means there is a close relation between target and output. Criteria 3 show network output errors. The range error value is close to zero $(-0.4-0.6)$. According to ANN Criteria it can be say that the proposed model is valid. All the results are shown in below.

The example result of simulation for Soekarno Hatta Airport, taking into account 2012 air traffic, is given in the following table. Pollutants considered were $\mathrm{CO}, \mathrm{HC}$,

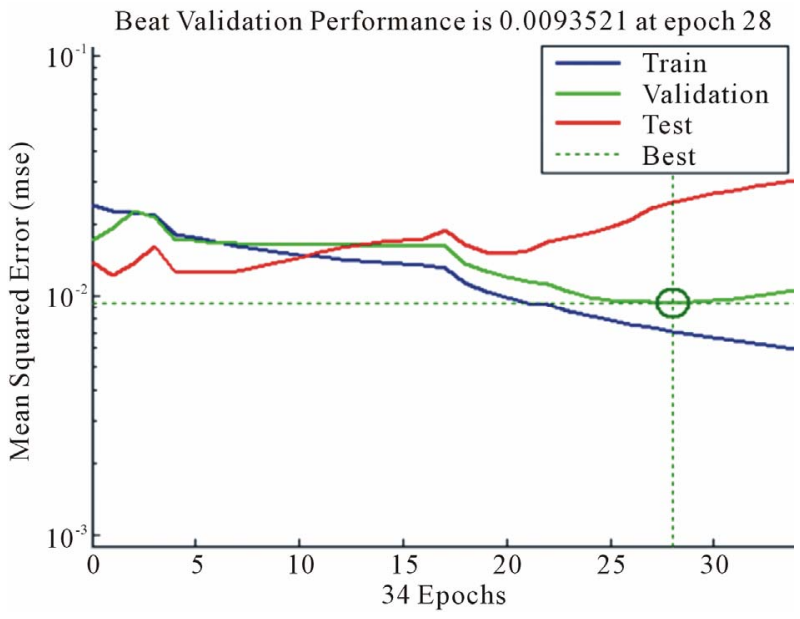

Figure 5. Criteria 1. 

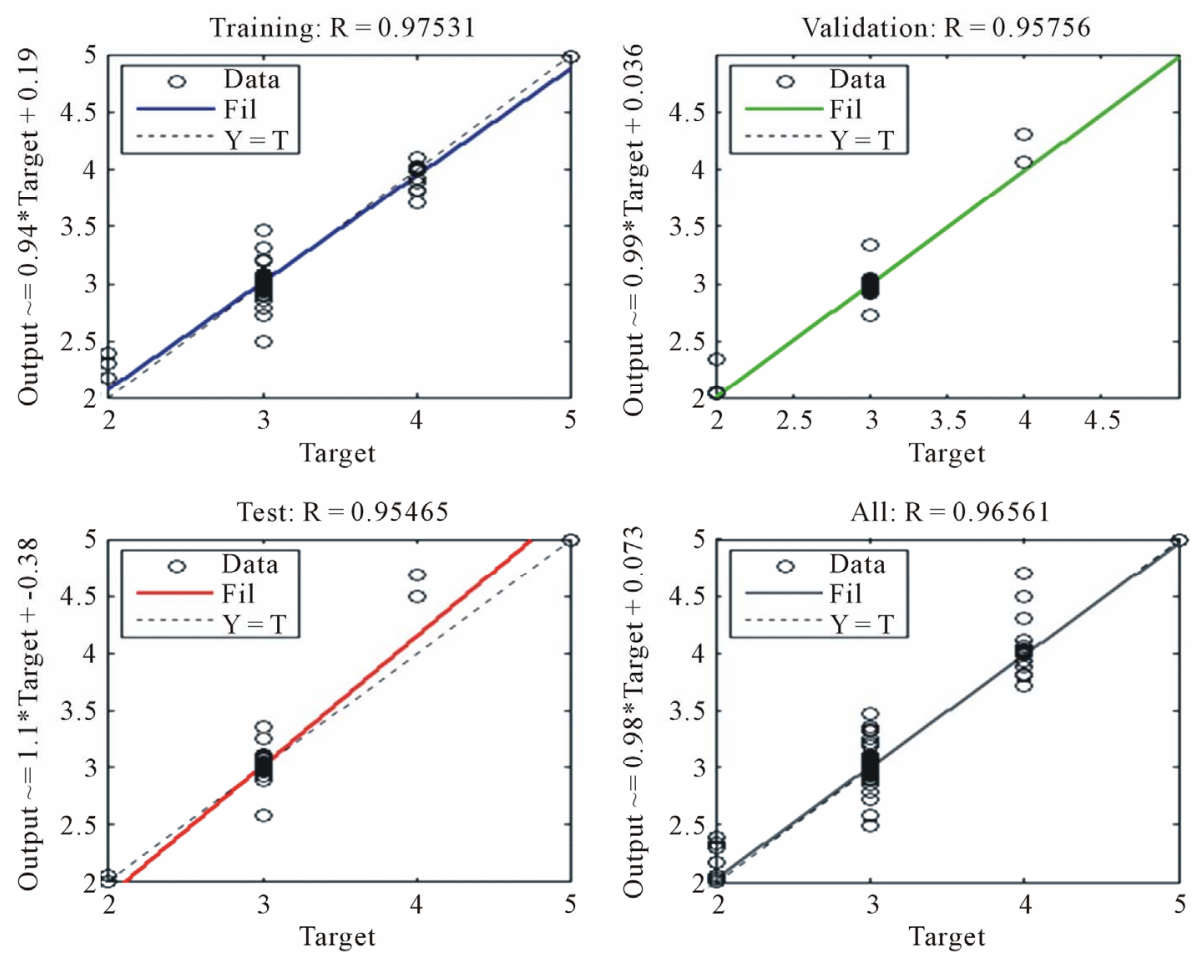

Figure 6. Criteria 2.

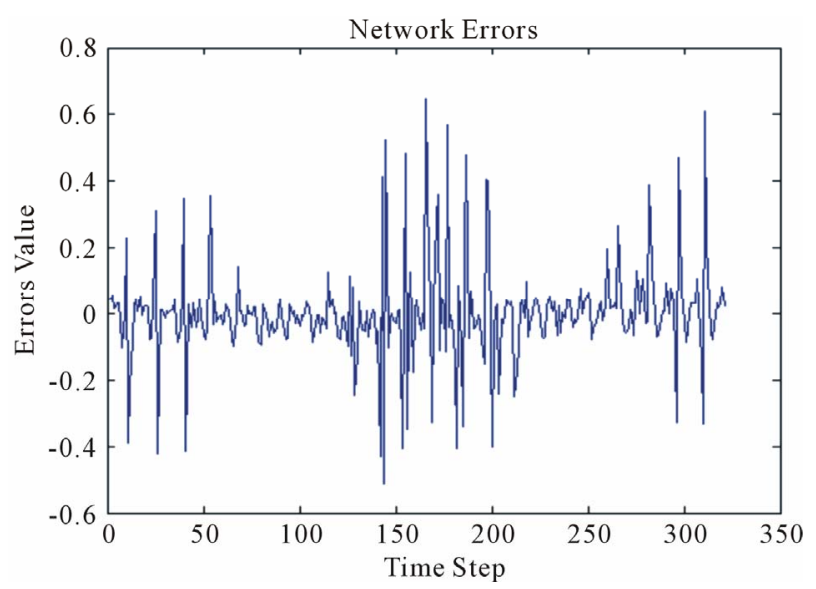

Figure 7. Criteria 3.

$\mathrm{NO}_{\mathrm{x}}$ and $\mathrm{SO}_{\mathrm{x}}$.

\begin{tabular}{ccccc}
\hline $\begin{array}{c}\text { ANN } \\
\text { calculation }\end{array}$ & $\mathrm{CO}(\mathrm{t} / \mathrm{y})$ & $\mathrm{HC}(\mathrm{t} / \mathrm{y})$ & $\mathrm{NO}_{\mathrm{x}}(\mathrm{t} / \mathrm{y})$ & $\mathrm{SO}_{\mathrm{x}}(\mathrm{t} / \mathrm{y})$ \\
\hline Aircraft & 3025261 & 137216 & 1640890 & 145823 \\
\hline
\end{tabular}

It corresponds to an increase by $6 \%$ of pollutant emissions a year since 2009 .

\section{Conclusions}

Neural network model has been performed to assess en- vironmental effects and impacts of air traffic on populations leaving around Soekarno Hatta International Airport-Cengkareng Indonesia. Assessment methods consisting of statistical analysis, internal criteria of the neural network method proved the high quality of the model outputs. ANN was used with the best architecture model 4-10-1. The suggested model has been validated by numerical processing and experimental date. In Criteria 1, best validation performance is achieved at epoch 28 (Mean Squared Error is less than 1\%). The correlation (Criteria 2) between target and output is validated at $\mathrm{R}=$ $96 \%$. There is a close relation between target and outputs. Criteria 3 show network output errors closed to zero. For this developed model, concentration grid area was $1 \mathrm{~km}^{2}$. The result map effect around this airport was a fine structure to be considered on the area of $308 \mathrm{~km}^{2}$.

In addition, a sophisticated method has to be developed; it would allow the modeling of the effects of nonISA temperature and pressure conditions at the airport. Particular assumptions concerning linearity variation of emissions with the thrust level have to be avoided. Modeling of non-linear variations of thrust settings has to be improved. Further research is needed with the aim to enlarge the scheme of the ANN model by increasing its input variables and a refinement of the grid around airport. This is one of the major key defining environmental capacities of an airport that should be applied by Indonesian airport authorities and international airports. These 
would institute policies to manage or reduce pollutant emissions considering population and income growth to be socially positive.

\section{REFERENCES}

[1] International Civil Aviation Organization (ICAO), “Airport Local Air Quality Guidance Manual,” 2007. http://www.icao.int/icaonet/dcs/9889/9889_en.pdf

[2] International Civil Aviation Organization (ICAO), "Environmental Report," 2007.

http://www.icao.int/environmental-protection/.../ENV_Re port_2010.pdf

[3] European Environmental Agency (EEA), "Emission Inventory Guidebook," 2009.

http://www.eea.europa.eu/themes/air/emep-eea-air-pollut ant-emission-inventory-guidebook/emep

[4] Federal Aviation Administration (FAA), "Office Environment and Energy, Aviation \& Emissions A Primer," 2005.

http://www.faa.gov/regulations_policies/policy_guidance/ envir_policy/media/aeprimer.pdf

[5] M. Dameris, V. Grewe, I. Kohler, P. Sausen, C. Bruehl, J. Grooss and B. Steil, "Impact of Aircraft $\mathrm{NO}_{\mathrm{x}}$ Emissions on Tropospheric and Stratospheric Ozone, Part II: 3-D Model Results," Atmospheric Environment, Vol. 32, No. 18,1998 , pp. 3185-3199. doi:10.1016/S1352-2310(97)00505-0

[6] B. E. Anderson, C. Gao and D. R. Blake, "Hydrocarbon Emissions from a Modern Commercial Airliner," Atmospheric Environment, Vol. 40, No. 19, 2006, pp. 36013612. doi:10.1016/j.atmosenv.2005.09.072

[7] J. S. Kurniawan and S. Khardi, "Comparison of Methodologies Estimating Emissions of Aircraft Pollutants, Environmental Impact Assessment around Airports," Environmental Impact Assessment Review, Vol. 31, No. 3, 2011, pp. 240-252. doi:10.1016/j.eiar.2010.09.001

[8] Federal Aviation Administration (FAA), "Air Quality Procedures for Civilian Airports and Air Force Bases, Appendix D: Aircraft Emission Methodology," 1997. http://www.faa.gov/regulations_policies/policy_guidance/ envir_policy/airquality_handbook/media/Handbook.pdf

[9] M. Gauss, I. S. A. Isaksen, D. S. Lee and O. A. Sovde, "Impact of Aircraft $\mathrm{NO}_{\mathrm{x}}$ Emissions on the AtmosphereTradeoffs to Reduce the Impact," Atmospheric Chemistry and Physics, Vol. 5, 2005, pp. 12255-12311. doi:10.5194/acpd-5-12255-2005

[10] Federal Aviation Administration (FAA), "Emission Dispersion Modeling System," 2009. http://www.faa.gov/about/office_org/headquarters_offices /aep/models/

[11] International Civil Aviation Organization (ICAO), "International Standards and Recommended Practices," Environmental Protection Annex 16, Volume II Aircraft Engine Emissions, 2nd Edition, ICAO, Montréal, 1993.
[12] International Civil Aviation Organization (ICAO), "Aircraft-Operations-Flight-Procedures,” Doc-8168-Vol. 1, 5th Edition, ICAO, Montréal, 2006.

[13] International Civil Aviation Organization (ICAO), "Annex-16-Vol-2-3rd-Edition, Aircraft Engine Emissions," 2008.

www.icao.int/environmental-protection/technology-stand ards_FR.aspx

[14] J. G. J. Olivier, "Inventory of Aircraft Emissions: A Review of Recent Literature," Report No. 736301 008, National Institute of Public Health and Environmental Protection, Bilthoven, 1991

[15] S. Khardi, "Development of Innovative Optimized Flight Paths of Aircraft Takeoffs Reducing Noise and Fuel Consumption," Acta Acustica United with Acustica, Vol. 97, No. 1, 2011, pp. 148-154.

[16] S. Khardi and L. Abdallah, "Optimization Approaches of Aircraft Flight Path Reducing Noise: Comparison of Modeling Methods," Applied Acoustics, Vol. 73, No. 4, 2012, pp. 291-301. doi:10.1016/j.apacoust.2011.06.012

[17] ALAQS, “Airport Local Air Quality Studies," 2009. http://www.isa-software.com/Alaqsstudy

[18] Sourdine II WP5, “Airport Noise and Emission Modeling Methodology," 2005.

http://www.sourdine.org/documents/public/SII_WP5_D52_v10.pdf

[19] Environmental Protection Agency (EPA), "Evaluation of Air Pollutant Emissions from Subsonic Commercial Jet Aircraft," 1999.

http://www.epa.gov/fedrgstr/EPA-AIR/2005/November/ Day-17/a22704.htm

[20] S. Baughcun, et al., "Scheduled Aircraft Emission Inventories for 1992. Database Development and Analysis," NASA Contract Report No. 4700, NASA Langley Research Centre, Washington DC, 1996.

[21] A. Cochocki and R. Unbehauen, "Neural Networks for Optimization and Signal Processing," John Wiley \& Sons, Inc., New York, 1993.

[22] M. Gevrey, I. Dimopoulos and S. Lek, "Review and Comparison of Methods to Study the Contribution of Variables in Artificial Neural Network Models," Ecological Modeling, Vol. 160, No. 3, 2003, pp. 249-264. doi:10.1016/S0304-3800(02)00257-0

[23] P. D. Wasserman, "Advanced Methods in Neural Computing," John Wiley \& Sons, Inc., New York, 1993.

[24] Z. H. Zhou, J. Wu and W. Tang, "Ensembling Neural Networks: Many Could Be Better than All," Artificial Intelligence, Vol. 137, No. 1-2, 2002, pp. 239-263.

[25] H. White, "Artificial Neural Networks: Approximation and Learning Theory," Blackwell Publishers, Inc., Cambridge, 1992.

[26] B. D. Ripley, "Pattern Recognition and Neural Networks," Cambridge University Press, Cambridge, 1996. 